\title{
CONSTRUÇÃO DE GRÁFICOS DE BARRAS A PARTIR DE DIFERENTES RECURSOS: LÁPIS E PAPEL E SOFTWARE EXCEL
}

\section{CONSTRUCTION OF BAR GRAPHICS FROM DIFFERENT RESOURCES: PENCILS AND PAPER AND SOFTWARE EXCEL}

\author{
Marcília Elane do Nascimento Pontes \\ Universidade Federal de Pernambuco - UFPE \\ marciliaelane@hotmail.com \\ Gilda Lisbôa Guimarães \\ Universidade Federal de Pernambuco - UFPE \\ gilda.lguimaraes@gmail.com
}

\begin{abstract}
Resumo
Esta pesquisa buscou investigar a aprendizagem de alunos do $5^{\circ}$ ano do Ensino Fundamental em relação à compreensão da construção de gráficos de barra, a partir de tabelas, utilizando os recursos: lápis e papel e o software Excel. Para isso, alunos de quatro turmas de escolas públicas de Paulista/Pernambuco participaram de um teste diagnóstico, uma sequência de ensino e um pós-teste. Duas turmas participaram dessa intervenção utilizando lápis e papel para a construção de gráficos e as outras duas utilizando o software Excel. Nessas intervenções, foi vivenciada a construção de gráficos a partir de tabelas simples, de dupla entrada e com grandezas numéricas diferentes. Foram observados avanços qualitativos em relação à representação dos dados em um gráfico de barras para os dois grupos e não houve diferença estatística significativa entre os recursos utilizados. Cada tipo de recurso contribuiu para o desenvolvimento de um tipo de habilidade, o que nos leva a crer que ambos deveriam ser estimulados no processo de ensino aprendizagem dos conhecimentos estatísticos.
\end{abstract}

Palavras-chave: Educação Estatística. Gráficos. Excel. Lápis e Papel. Anos Iniciais.

\begin{abstract}
This research aims to investigate the learning of students in the 5th grade of primary school in relation to understanding the construction of bar charts from tables using two types of resources: pencil and paper or the Excel software. Students from four classes in public schools in Paulista / Pernambuco participated in a diagnostic test, a teaching sequence and a post-test. Two classes participated in this intervention using pencil and paper to build graphs and the other two classes using Excel software. In these interventions, the construction of graphs was experienced from simple and double entry tables and with different numerical quantities. Qualitative advances were observed in relation to the representation of the data in a bar graph for the two groups and there was no statistically significant difference between the resources used. Each type of resource contributes more to a type of skill, which leads us to believe that both should be stimulated in the teaching-learning process of statistical knowledge.
\end{abstract}

Keywords: Statistical Education. Graphs. Excel. Pencil and paper. Primary school. 


\section{INTRODUÇÃO}

A Estatística está presente nas mais diversas situações do nosso cotidiano. Saber interpretar e analisar informações é fundamental para que qualquer cidadão possa compreender melhor o que se passa à sua volta e, desse modo, interagir na sociedade de forma mais questionadora. A capacidade de analisar criticamente as informações divulgadas pela mídia, assim como tomar decisões baseadas em dados, é aqui entendida como Letramento Estatístico (GAL, 2002).

Diante desse contexto, entendemos que o ensino de Estatística é de grande importância para a formação do estudante e deve contemplar questões pertinentes para uma vida em sociedade. Logo, faz-se necessário que a escola proporcione aos estudantes, desde os primeiros anos da escola básica, a formação de conceitos que o auxiliem no exercício de sua cidadania.

O ensino de Estatística teve início nos currículos na década de 1980. No Brasil, o conteúdo de Estatística foi inserido primeiramente no Ensino Fundamental, pelos Parâmetros Curriculares Nacionais (BRASIL, 1997), com a denominação de tratamento da informação. Atualmente, no Brasil, o documento que orienta a construção dos currículos é a Base Nacional Comum Curricular - BNCC (BRASIL, 2017). Esse documento destaca que os primeiros passos envolvem o trabalho com a coleta e a organização de dados de uma pesquisa de interesse dos alunos. A leitura, a interpretação e a construção de tabelas e gráficos têm papel fundamental, bem como a forma de produção do texto escrito para a comunicação de dados. É esperado que as crianças, ao terminarem o $5^{\circ}$ ano, compreendam e saibam utilizar uma linguagem simples das ideias fundamentais da Estatística e que sejam capazes de organizar dados em tabelas simples, de dupla entrada e gráficos.

Acreditamos que o trabalho com Estatística, em sala de aula, deve promover discussões e reflexões para a solução de uma situação-problema real, utilizando ou não as tecnologias para a consolidação do ensino e aprendizagem de Estatística. Atualmente, são incontáveis as pesquisas relacionadas à Estatística na perspectiva da formação inicial de professores ou estudo comparativo dos currículos. Porém, no que diz respeito às práticas que utilizam a tecnologia para o ensino da Estatística, ainda existem lacunas a serem preenchidas com produções acadêmicas que abordem os diversos aspectos relacionados tanto a aprendizagem, quanto ao ensino desse conhecimento na escola.

Estudos recentes (CAMPÊLO, 2014; DIAS, 2016; DINIZ, 2016; ESTEVAM; KALINKE, 2013) têm mostrado que a utilização das tecnologias para a consolidação do ensino e aprendizagem de Estatística pode ser um caminho interessante para desenvolver, 
especialmente, a análise crítica a respeito dos dados produzidos. A tecnologia está presente nas diversas áreas de conhecimento e os processos pedagógicos não devem ficar alheios aos avanços da ciência e da tecnologia. Ensinar, nos dias de hoje, requer práticas diferenciadas e metodologias que considerem os estudantes imersos no contexto social atual, que é um universo permeado pelas tecnologias digitais. Assim, a pesquisa pretende contribuir com os processos relacionados ao desenvolvimento de estudos sobre o ensino de Estatística, com foco na sala de aula dos anos iniciais do Ensino Fundamental.

\section{Construção e representação de gráficos de barras}

O gráfico de barras é uma das formas de representação de dados estatísticos. Nesse tipo de gráfico, as barras podem ser representadas na forma horizontal ou vertical, sendo essa última a mais comum nos livros didáticos e avaliações externas nos anos iniciais do Ensino Fundamental no Brasil. Esse tipo de representação permite que o leitor compare quantidades expressas por barras retangulares uniformes quanto à sua largura, mas com altura proporcional à quantidade representada. Para construir esse tipo de gráfico traçamos um sistema de eixos perpendiculares que se interceptam num ponto em comum. Os eixos devem ser sempre legendados, pois um deles expressa a quantidade e o outro as variáveis. Curcio (1989) já afirmava que os gráficos providenciam um meio para comunicar e classificar dados, uma vez que permitem a comparação e facilitam demonstrações matemáticas as quais dificilmente seriam compreendidas caso se recorresse apenas à sua forma numérica.

Gráficos, tabelas e infográficos são frequentemente utilizados para apresentar dados nas mais diferentes situações de nossas vidas, sendo essas no contexto escolar ou não, o que reforçam a urgência das crianças aprenderem a ler, interpretar e construir gráficos como uma maneira de se tornarem cidadãos informados, críticos e reflexivos.

Alguns estudos apresentam como os alunos dos anos iniciais do Ensino Fundamental compreendem e aprendem acerca de representações gráficas. Guimarães (2002) investigou o que os alunos da $3^{\mathrm{a}}$ série do Ensino Fundamental (atualmente turma do $4^{\mathrm{o}}$ ano) sabiam sobre interpretação e construção de gráficos. Foi observado que a maior dificuldade dos alunos era compreender a escala, tanto na interpretação como na construção dos gráficos. Da mesma forma, Cavalcanti e Guimarães (2010), investigando adultos e crianças que frequentavam os anos iniciais do Ensino Fundamental, também observaram dificuldades em relação à compreensão de escala representada em gráficos de barras e de linha. Os dois estudos evidenciam que estudantes, dos anos iniciais do Ensino Fundamental, apresentam 
dificuldades em compreender os valores implícitos representados em uma escala, ou seja, compreender a proporcionalidade entre os valores expressos em uma reta numérica.

Outra dificuldade em relação à compreensão de representação em gráficos e tabelas foi investigada por Bivar e Selva (2011). As autoras investigaram estudantes do $3^{\circ}$ e $5^{\circ}$ ano do Ensino Fundamental, ao realizarem transformação entre diferentes representações, como do gráfico para a tabela e da tabela para o gráfico, e evidenciaram o entrave dos alunos com esse tipo de atividade, visto que eles tiveram dificuldade em compreender as especificidades de cada representação.

Entretanto, Evangelista e Guimarães (2015) realizaram um estudo de intervenção de ensino e identificaram que os alunos dos anos iniciais, quando levados a refletir sobre escalas, demonstram capacidade e facilidade para aprender, alertando sobre o papel da escola acerca de um ensino sistemático para que os alunos possam ser leitores e produtores críticos de informações veiculadas em gráficos.

Consideramos importante que os alunos sejam levados a compreender que para a construção de um gráfico de barras a partir de uma tabela, é preciso considerar as especificidades dessa representação. Os alunos devem registrar os eixos de coordenadas, realizar o registro da escala mais adequada para representar os dados, nomear os eixos e as barras, inserir o nome do gráfico e registrar a fonte. Portanto, é importante destacarmos a utilização dos diferentes recursos na construção do conhecimento estatístico, entre eles a adoção das tecnologias de informação e comunicação digitais como elementos facilitadores na consolidação desses conhecimentos.

\section{O uso das tecnologias digitais e comunicações no ensino de Estatística}

Atualmente, uma forma de auxiliar os alunos a compreender as representações gráficas tem sido valorizada - o uso de tecnologias digitais. Essas novas tecnologias potencializam as investigações de alunos e professores, propiciando, a eles, uma ferramenta de investigação que permite a construção de gráficos a partir de tabela. Uma dessas ferramentas é o software Excel, o qual está disponível em muitos computadores e notebooks. A utilização do recurso tecnológico possibilita aos alunos a experiência com uma forma diferente para aprender, já que usualmente eles utilizam apenas o lápis e papel.

Estudos recentes (BUENO; LIZIERO, BORUCH, KMITA, FRANCZAK, 2016; CARNEIRO; PASSOS, 2009; DIAS; SANTOS JÚNIOR, 2016; ESTEVAM; KALINKE, 2013; entre outros) apontam que o uso das novas tecnologias, em sala de aula, permite trabalhar com investigação e experimentação na Estatística, pois possibilita ao estudante 
vivenciar experiências, interferir e construir o próprio conhecimento. A implementação de investigações estatísticas em sala de aula, recorrendo aos recursos tecnológicos, poderá beneficiar o desenvolvimento do letramento estatístico dos alunos, levando-os a serem cidadãos letrados estatisticamente, críticos e capazes de tomarem decisões pessoais e sociais estatisticamente confiáveis.

Apesar de não ser um software educativo, o Excel apresenta um grande potencial para o ensino de Estatística nos anos iniciais de escolarização. Compreendemos que o uso do software ajuda na construção de diferentes formas de representação como gráfícos, planilhas, banco de dados e tabelas e, dessa maneira, o aluno interage com outros recursos diferentes do uso do papel, lápis, borracha e régua. Nesse contexto, um sistema de computador tem muitas vantagens valiosas sobre a tecnologia tradicional de papel e lápis, incluindo mudanças fáceis e interativas nas representações (BEN-ZVI, 2011).

Alguns estudos vêm sendo realizados utilizando o software Excel para o ensino de Estatística. Identificamos que a maior parte desses estudos são realizados nos anos finais do Ensino Fundamental ou no Ensino Médio (BIANCHINI; BISOGNIN; SOARES, 2015; BUENO et al., 2016; entre outros). As pesquisas evidenciam a possibilidade do uso do software como auxiliar na construção de tabelas e gráficos para alunos do Ensino Fundamental e ressaltam que pode ser um bom recurso na compreensão das diferentes representações estatísticas.

Como é prescrito na BNCC (BRASIL, 2017), as crianças, ao terminarem os anos iniciais do Ensino Fundamental, devem compreender e saber utilizar ideias fundamentais da Estatística. Para tal, devem realizar pesquisas, iniciando pela formulação de questões, passando pela coleta e organização de dados em tabelas simples, de dupla entrada e/ou gráficos, finalizando na interpretação e apresentação dos resultados das questões investigadas.

Acreditamos que o uso de recursos tecnológicos e outros materiais didáticos na prática pedagógica devem ser considerados pelo professor como um elemento desafiador da sala de aula, permitindo um ambiente de reflexão e de construção do conhecimento, mas não apenas para tornar a aula agradável ao aluno. Assim, neste estudo tivemos por objetivo investigar a aprendizagem de alunos do $5^{\circ}$ ano do Ensino Fundamental, em relação à compreensão da construção de gráficos de barras, a partir de tabelas, utilizando dois tipos de recursos: lápis e papel e o software Excel. 
Pontes, M. E. N.; Guimarães, G. L.

\section{MÉTODO}

A pesquisa foi desenvolvida em quatro turmas de duas escolas públicas do município do Paulista, Pernambuco. As escolas foram escolhidas por conveniência de localização geográfica e também pela disponibilidade dos recursos tecnológicos que seriam utilizados no desenvolvimento da pesquisa. Nesse município, o currículo apresenta as mesmas prescrições da BNCC para o ensino de estatística.

Esse estudo se configura como uma pesquisa experimental na qual são propostos um teste inicial, um processo de intervenção com a mesma sequência de atividades, porém com dois tipos de recursos: lápis e papel e software Excel e, finalmente, um pós-teste. Esse processo ocorreu no prazo de um mês.

Iniciamos realizando um pré-teste com 74 alunos, buscando identificar os conhecimentos deles sobre construção de gráficos de barras a partir de tabelas (Figura 1). As tabelas apresentadas nas atividades eram semelhantes às construídas pelos professores em sala de aula e propostas nos livros didáticos utilizados nas turmas dos $5^{\circ}$ anos do Ensino Fundamental no município do Paulista.

$\mathrm{Na}$ Atividade 1, esperávamos que os alunos representassem um gráfico de barras simples, com escala não unitária, levando em consideração a proporcionalidade das barras e registrassem os elementos que constituem um gráfico: título, sistema de eixo nomeado, escala, nome das barras e fonte. Para a Atividade 2, tínhamos a expectativa de que os alunos construíssem um gráfico de barras duplas, a partir de uma tabela de dupla entrada, registrando os elementos constituintes de um gráfico de barras duplas.

Figura 1 - Atividades do pré-teste

Observe as informações presentes na tabela e construa um gráfico de barras. Atividade 1

Atividade 2

PESO DOS ANIMAIS SILVESTRES

PERCENTUAL DE PESSOAS QUE JOGAM OS JOGOS ELETRÔNICOS

\begin{tabular}{|l|c|}
\hline \multicolumn{1}{|c|}{ ESPÉCIE } & PESO (KG) \\
\hline GUAXINIM & 5 \\
\hline LOBO GUARÁ & 25 \\
\hline TATU & 6 \\
\hline JACARÉ & 70 \\
\hline PORCO ESPINHO & 5 \\
\hline LONTRA & 35 \\
\hline
\end{tabular}

\begin{tabular}{|c|c|c|}
\hline \multirow{2}{*}{ ANOS } & \multicolumn{2}{|c|}{ JOGADORES } \\
\cline { 2 - 3 } & HOMENS & MULHERES \\
\hline 2013 & 60 & 41 \\
\hline 2015 & 55 & 47 \\
\hline 2016 & 47 & 55 \\
\hline 2017 & 45 & 53 \\
\hline
\end{tabular}

Fonte:http://escolabrasileiradegames.com.br/blog/pesquisa-gamebrasil-2017-o-perfil-do-gamer-brasileiro-mobile-smartphone-tablet

Fonte: http://pt.slideshare.net/zezinhoje/supertrunfo-animais-silvestres 
$\mathrm{Na}$ fase da intervenção, foi proposta uma sequência de atividades para as turmas. Com o objetivo de mediar a intervenção de ensino, dividimos as quatro turmas em dois grupos. Para o grupo 1 (G1), as intervenções foram realizadas solicitando aos alunos que resolvessem as situações propostas utilizando como recurso o lápis e papel, enquanto para o grupo 2 (G2), as intervenções foram realizadas solicitando aos alunos que resolvessem as situações propostas utilizando como recurso o software Excel. A pesquisadora participante, que é também professora dessa rede, assumiu o papel de professora para essa intervenção.

Cada tipo de recurso foi experimentado em duas turmas com alunos e professores diferentes. A escolha em trabalhar com duas turmas em cada grupo foi para evitar que o trabalho desenvolvido por uma professora ou a característica de uma turma pudessem levar a uma melhor aprendizagem, independente do recurso utilizado. Assim, após realizarmos o pré-teste individual, ou seja, uma diagnose do que os alunos sabiam, realizamos um teste estatístico (Anova) para verificar se havia diferenças estatisticamente significativas entre as quatro turmas.

O processo de intervenção ocorreu em dois encontros com cada uma das turmas. No primeiro encontro, propusemos a interpretação de dados apresentados em tabelas simples e a construção de gráfico de barras simples. No segundo encontro, propusemos a interpretação de dados apresentados em tabelas de dupla entrada e construção de gráfico de barras múltiplas. Vamos detalhar as atividades mais adiante.

Realizamos o pós-teste individual, depois de terminado o processo de intervenção de ensino (Figura 2). Utilizamos como recurso o lápis e o papel, para todas as turmas responderem às questões semelhantes às do pré-teste.

Figura 2 - Atividades do pós-teste

\section{Observe as informações presentes na tabela e construa um gráfico de barras.}

Atividade 1

POPULAC̣̃̃O DE ANIMAIS DE ESTIMAC̣ÃO NO BRASIL

\begin{tabular}{|l|c|}
\hline ANIMAL & QUANTIDADE \\
\hline CACHORRO & 50 \\
\hline GATO & 27 \\
\hline PASSARINHO & 40 \\
\hline PEIXE & 18 \\
\hline COBRA & 3 \\
\hline
\end{tabular}

Fonte: IBGE (INSTITUTO BRASILEIRO DE GEOGRAFIA E ESTATÍSTICAS).
Atividade 2

Quantidade de cartões recebidos pelas seleções na fase de grupo em cinco edições de copas do mundo de futebol FIFA

\begin{tabular}{|l|c|c|}
\hline \multirow{2}{*}{ SELEÇĀo } & \multicolumn{2}{|c|}{ TIPO DE CARTÃo } \\
\cline { 2 - 3 } & AMARELO & VERMELHO \\
\hline França & 28 & 1 \\
\hline Brasil & 20 & 1 \\
\hline Espanha & 18 & 0 \\
\hline Alemanha & 30 & 2 \\
\hline Itália & 27 & 2 \\
\hline
\end{tabular}

Fonte: site da Fifa, disponivel em http://www.fifa.com 


\section{O que foi realizado durante as intervenções?}

No primeiro dia da intervenção, foram propostas duas atividades com tabelas simples, ou seja, com apenas uma variável. Na atividade 1 , foi apresentada uma tabela simples "Número de filhotes por ninhada", com valores inferiores a 10, na qual era possível construir uma escala unitária. As tabelas que selecionamos apresentavam dados pertinentes ao contexto dos alunos, o que facilita o entendimento dos dados apresentados. Ao escolhermos trabalhar com tabelas que expressam dados reais, objetivamos dar destaque ao momento de análise e interpretação dos dados apresentados a fim de desenvolver com os alunos algumas habilidades do letramento estatístico.

Iniciamos com a leitura e interpretação dos dados apresentados na tabela. Para facilitar a visualização dos dados apresentados na representação tabular, a pesquisadora copiou a tabela no quadro da sala de aula. Em seguida, realizou a leitura da atividade, explanou sobre os dados apresentados e foi questionando os alunos sobre o que as informações comunicavam. A pesquisadora solicitou que as duplas construíssem um gráfico de barras a partir dos dados apresentados na tabela, como solicitava o enunciado da atividade. No decorrer desse período, a pesquisadora ia passando de dupla em dupla acompanhando como estava o desenvolvimento da atividade. Durante a construção do gráfico de barras pelos alunos, a pesquisadora ia provocando reflexões sobre os elementos constituintes da representação como: o título do gráfico, registro dos eixos, nome das barras, fonte dos dados e, principalmente, o registro do eixo numérico, chamado de escala. Os alunos se mostraram concentrados e interessados em registrar a representação gráfica. Após a resolução, a pesquisadora levou-os a comparar as produções e sistematizou as características da representação gráfica no quadro.

Em seguida, da mesma forma, foi apresentada a Atividade 2, a qual trazia uma tabela simples sobre "Redes sociais mais populares no Brasil em 2018" com valores a serem representados na escala, que variavam de 20 a 130, o que exigia do aluno a criação de uma escala diferente da unitária em função da grandeza numérica. Nesse primeiro dia, a interação com os alunos teve duração aproximada de 100 minutos.

Iniciamos contextualizando sobre as redes sociais, aproximando a temática abordada às vivências dos alunos. Após, solicitamos aos alunos o registro dos dados apresentados na tabela em um gráfico de barras e fomos orientando a construção da representação, como na atividade anterior. Pudemos perceber que os alunos interagiram melhor com os dados apresentados e foram realizando a atividade com mais segurança, fato esse que pode ser explicado por terem vivenciado a atividade anterior. Terminado o momento de registro por 
parte dos alunos, a pesquisadora registrou no quadro a representação do gráfico de barras e foi chamando a atenção para os elementos que constituem um gráfico de barras simples.

No segundo dia da intervenção de ensino, foram propostas duas atividades com tabelas de dupla entrada, envolvendo duas variáveis, o que resulta na construção de um gráfico de barras múltiplas. Novamente, a grandeza numérica variou entre as duas atividades propostas nesse dia. A pesquisadora abordou o modo como os dados estavam representados, denominando a tabela de dupla entrada e explicando que nessa atividade teríamos mais variáveis para analisar.

$\mathrm{Na}$ atividade 1, a tabela "Número de pessoas no Brasil (em milhões), em 2010, por gênero" exigia que os alunos representassem em um gráfico de barras a quantidade de sujeitos a partir do gênero e de sua faixa etária. Destacamos, nessa atividade, a fonte dos dados, trazendo a discussão sobre a origem das informações e o fato de representar dados reais veiculados em nossa sociedade. Nesse momento, a pesquisadora comunicou sobre o Instituto Brasileiro de Geografia e Estatística - IBGE, destacando a função do instituto e os tipos de dados que disponibilizam.

Em seguida, a pesquisadora solicitou que os alunos, em duplas, construíssem o gráfico de barras duplas. Ela destacou para os estudantes que cada barra necessita obrigatoriamente ser proporcional com relação a sua frequência, bem como os orientou no sentido de que, ao construir um gráfico, no qual o número da amostra é muito grande, devese fazer uso de escalas proporcionais. Nessa atividade, foi possível observar os alunos dialogando entre si, elaborando hipóteses e tecendo conclusões com relação aos dados apresentados na tabela. Assim, atribuíam significado ao que estava sendo ensinado, o que reafirma o posicionamento de Carvalho (2009), ao enunciar que a escolha de atividades pelo professor e o modo como os alunos se envolvem na resolução é determinante para a qualidade do seu desempenho e para as atitudes que lhes estão associadas. Fernandes, Viseu, Fernandes, Silva e Duarte (2009) enfatizam que, além disso, a valorização do trabalho em grupo e a comunicação dos resultados de modo escrito e oral podem ser uma alternativa para melhoria do processo de ensino e aprendizagem.

Para finalizar esse momento, a pesquisadora registrou no quadro a representação do gráfico de barras duplas, etapa a etapa, aplicando todo o procedimento para registro da representação gráfica. Identificamos, durante uma andada pela sala, que vários alunos não registraram a legenda, título e a fonte do gráfico. Pois, assim como foi identificado no estudo de Fernandes (2014), os alunos demonstram muita dificuldade e nenhuma familiaridade com gráficos de barras duplas, insistindo na representação de dois gráficos em separado, cada um 
referente a um gênero.

Em seguida, iniciamos a Atividade 2, que abordava os "Casos de Dengue, Chikungunya e Zika no Nordeste nos anos de 2015 e 2016”. A escolha por essa atividade se deu para propormos a discussão de uma temática presente no cotidiano dos alunos. Utilizamos um mapa político do Brasil, para que eles pudessem refletir sobre os dados apresentados na tabela, levando-os a relacionar o número de casos das arboviroses com a extensão territorial dos estados. Os alunos se mostraram confusos com o registro da representação do gráfico de barras duplas, o que, de fato, é uma construção mais elaborada do que um gráfico de barras simples. Diante disso, fica evidente que os livros didáticos devem explorar não só atividades de interpretação, mas também de construção de escala, possibilitando aos alunos condições de desenvolverem tanto uma habilidade quanto a outra, visto que ambas se completam. Entendemos que os processos envolvidos na construção e interpretação de gráficos podem se complementar, uma vez que construir requer interpretação, mas nem sempre interpretar requer reflexões sobre a construção do gráfico (GUIMARÃES, 2002).

Nas turmas do G2, em que utilizamos como recurso o software Excel, iniciamos a atividade explanando que realizaríamos uma atividade na qual seria utilizado um software chamado Excel. Em seguida, apresentamos o software e algumas ferramentas que empregaríamos na realização da atividade. Em cada computador, já havíamos registrado as tabelas a serem utilizadas durante a intervenção de ensino. Durante todo o processo de intervenção, a pesquisadora estava com o software Excel aberto em seu notebook e explicava e mostrava os elementos conforme ia manipulando. Ela explicou como se daria o registro da representação gráfica utilizando o software Excel, comunicando que utilizaríamos a ferramenta inserir, a qual permite, a partir da seleção dos dados da tabela, realizar a inserção do gráfico correspondente. Orientamos os alunos a utilizarem o mouse para realizar a seleção dos dados apresentados na tabela. Depois de conferir se todos haviam conseguido selecionar os dados, orientamos para clicarem na barra de ferramentas em Inserir. Logo, surgiu na tela de cada computador um gráfico de barras. Momento que causou euforia nos alunos e todos começaram a falar ao mesmo tempo sobre essa vivência.

\section{Análise e discussão dos dados}

Começamos analisando o desempenho dos alunos no pré-teste e comparando se havia diferenças entre as turmas. Para corrigir as respostas dos alunos, consideramos a seguinte classificação: 0 (faz um desenho qualquer ou não constrói um eixo de coordenadas ou deixa 
em branco); 1 (na atividade 1 faz um eixo de coordenadas, registra as barras e coloca uma escala e na atividade 2 faz um gráfico para cada variável, colocando eixo de coordenadas, barras e uma escala) e 2 (na atividade 1 representa o eixo de coordenadas, as barras e uma escala correta e na atividade 2 representa o eixo de coordenadas com barras múltiplas e escala correta). Para verificar se as turmas apresentavam desempenho semelhante no préteste, foi realizada uma análise de variância (Anova) considerando o desempenho em função da turma. Não foi encontrada diferença significativa para o desempenho dos alunos [F (70, $3)=2,226 ; p=0,093]$. Esses resultados evidenciam que não havia diferença entre as turmas, o que possibilitou o modelo experimental proposto.

Em seguida, analisamos uma possível aprendizagem, comparando o pré-teste e pósteste, no intuito de indicar os avanços conquistados com o processo de intervenção de ensino. Realizamos uma análise de variância para investigar se havia diferença significativa entre o desempenho dos alunos considerando o recurso utilizado na intervenção (lápis e papel e Excel). Essa análise evidenciou que não houve diferença significativa no pós-teste para o desempenho entre os grupos de alunos $[F(63,1)=3,260 ; p=0,076]$.

Dessa forma, podemos afirmar que o recurso utilizado não foi um fator determinante para o melhor desempenho dos alunos no pós-teste. Ambos os grupos apresentaram um melhor desempenho no pós-teste, indicando que as intervenções levaram à aprendizagem, mas sem diferença entre os grupos.

\section{O que observamos sobre a aprendizagem dos alunos?}

A partir do que foi vivenciado no processo de intervenção de ensino, pudemos avaliar o desempenho dos alunos tanto no pré-teste como no pós-teste a partir da utilização dos dois recursos (Gráfico 1).

Gráfico 1 - Desempenho dos alunos no pré e no pós-teste a partir do recurso utilizado por fase

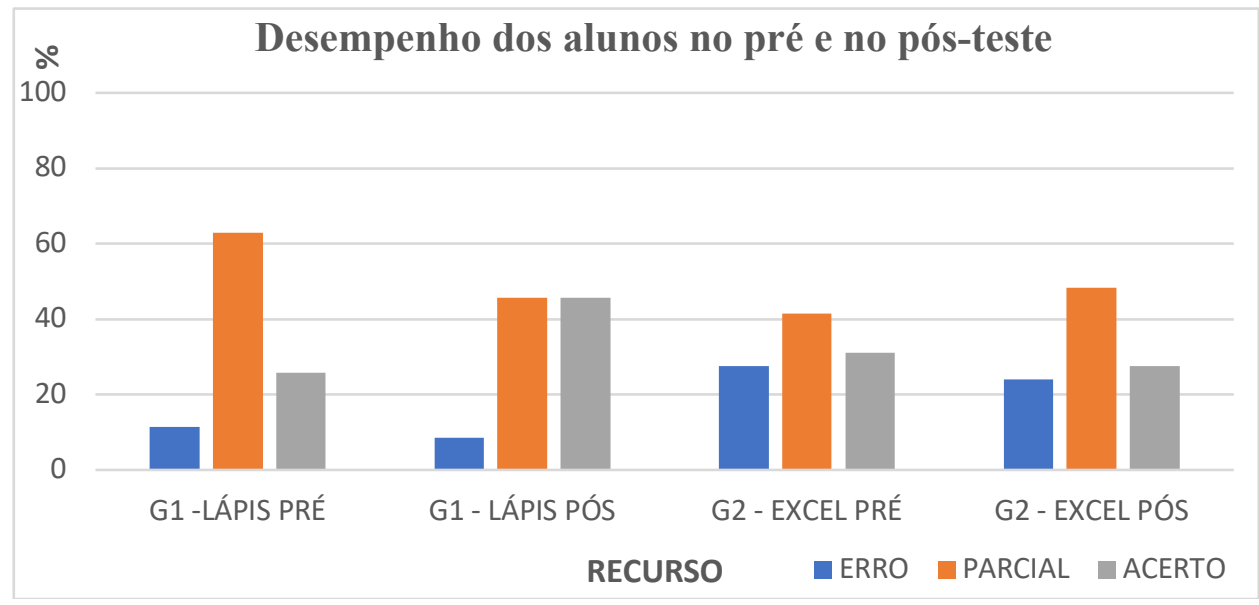

Fonte: as autoras 
Comparando os resultados, podemos observar que o G1, o qual utilizou como recurso o lápis e papel, obteve uma concentração de acertos parciais no pré-teste $(62,9 \%)$. No pósteste, pudemos observar que houve avanços na aprendizagem, uma vez que ocorreu a diminuição do quantitativo de erros e dos acertos parciais e aumento do quantitativo de acertos. Com relação ao desempenho do G2, percebemos que os acertos parciais aumentaram e os erros diminuíram. Entretanto, nos chamou a atenção a discreta diminuição dos acertos no pós-teste (de 31\% para 27,6\%). Esse dado pode ter ocorrido em função da decepção dos alunos em ter que realizar as atividades do pós-teste utilizando como recurso o lápis e papel, visto que tinham ficado muito felizes em construir no software Excel, manuseando o computador. Assim, podem ter aprendido a construir no Excel e não com lápis e papel.

Depois dessa primeira classificação das respostas dos alunos, sistematizamos os elementos constituintes de um gráfico de barras, para então classificar o que eles conseguiam realizar a partir dos conhecimentos já adquiridos, e o que conseguiram após o momento de intervenção de ensino. Consideramos os seguintes elementos constituintes de um gráfico de barras: representação gráfica dos dados, eixos, barras, escala, título e fonte. Em seguida, avaliamos cada atividade dos testes, comparando os resultados levantados no pré-teste e no pós-teste.

$\mathrm{Na}$ Atividade 1 dos testes (pré e pós), o primeiro elemento avaliado foi a representação dos dados registrada pelos alunos. Os alunos do G1 avançaram na compreensão da representação gráfica, pois a maioria deles $(78 \%)$, após a intervenção de ensino, construiu um gráfico. Já em relação ao desempenho do G2, verificamos uma discreta melhora de $41,6 \%$ para $48,4 \%$.

Nas respostas da Aluna A22, podemos perceber o avanço no registro da representação dos dados. No pré-teste, conforme registro de sua representação gráfica, ela apenas desenha as barras e as nomeia, sem considerar os demais elementos de um gráfico de barras; no pós-teste, identificamos que registra as barras, o título, os eixos e seus nomes (descritores) e representa a escala (apesar de apresentar problemas na proporcionalidade). 
Figura 3 - Resposta da Aluna A22, no pré-teste e no pós-teste


Fonte: as autoras

Avaliamos também se os alunos registravam o eixo de coordenadas, e pudemos perceber que houve uma diminuição no número de alunos que não registravam os eixos após a intervenção de ensino.

Em uma representação gráfica, nomear as barras é importante para que todos saibam quais são as categorias, ou seja, o que representa cada uma. Assim, analisamos se os alunos nomeavam ou não todas elas. Observamos que, já no pré-teste, a maioria dos alunos registravam os nomes das barras. Dessa forma, ficou constatado que essa é uma habilidade que já se mostra presente na construção de gráficos de barras pelos alunos do $5^{\circ}$ ano.

A escala constitui um componente fundamental para o entendimento do registro dos dados em uma representação gráfica. Conforme Guimarães (2002), a elaboração de um gráfico exige a compreensão da escala ou da unidade com a qual essa é organizada, uma vez que ela é uma das questões relevantes para entender as informações representadas nas exposições gráficas.

No pré-teste, identificamos que 36\% dos alunos do Grupo 1 e $30 \%$ dos alunos do Grupo 2 não registravam a escala (Figura 4). Já no pós-teste, observa-se uma diminuição desse tipo de resposta nos dois grupos (Figura 5).

Figura 4 - Representação sem escala

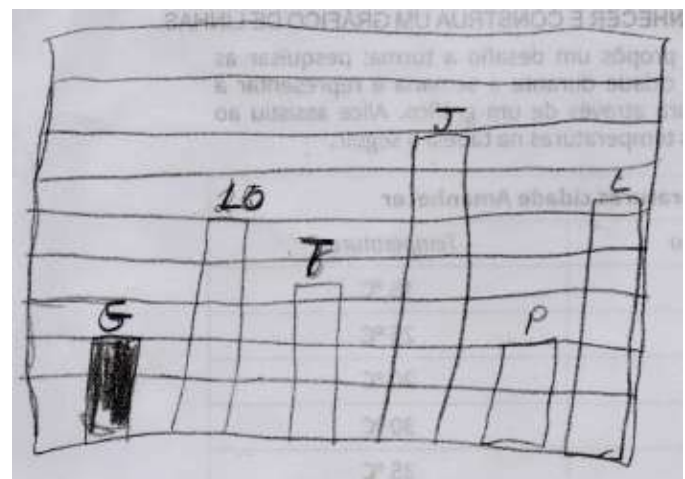

Figura 5 - Representação com escala

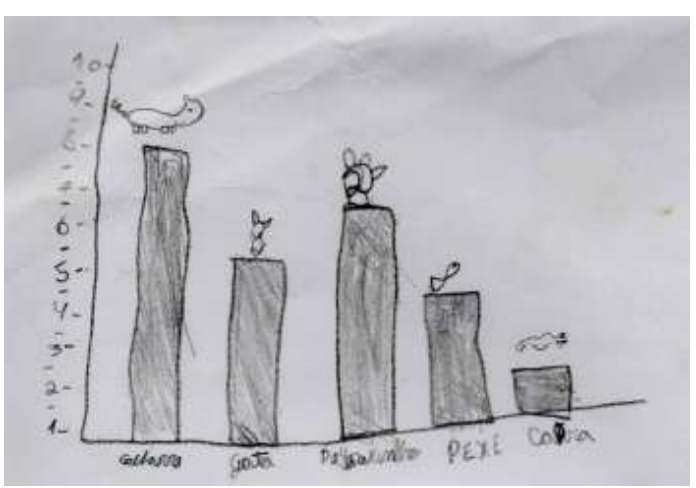

Fonte: as autoras 
O tipo de resposta mais frequente no pré-teste foi o registro da escala a partir da cópia dos valores apresentados na tabela sem, no entanto, apresentar preocupação com a proporcionalidade entre os intervalos da reta numérica, o que é fundamental (Figura 6). No pós-teste, há uma diminuição desse tipo de erro e um aumento no registro da escala corretamente, unitárias ou não para o G1. Porém, para o G2, há uma concentração desse tipo de resposta.

Figura 6 - Registro da escala sem proporcionalidade no intervalo

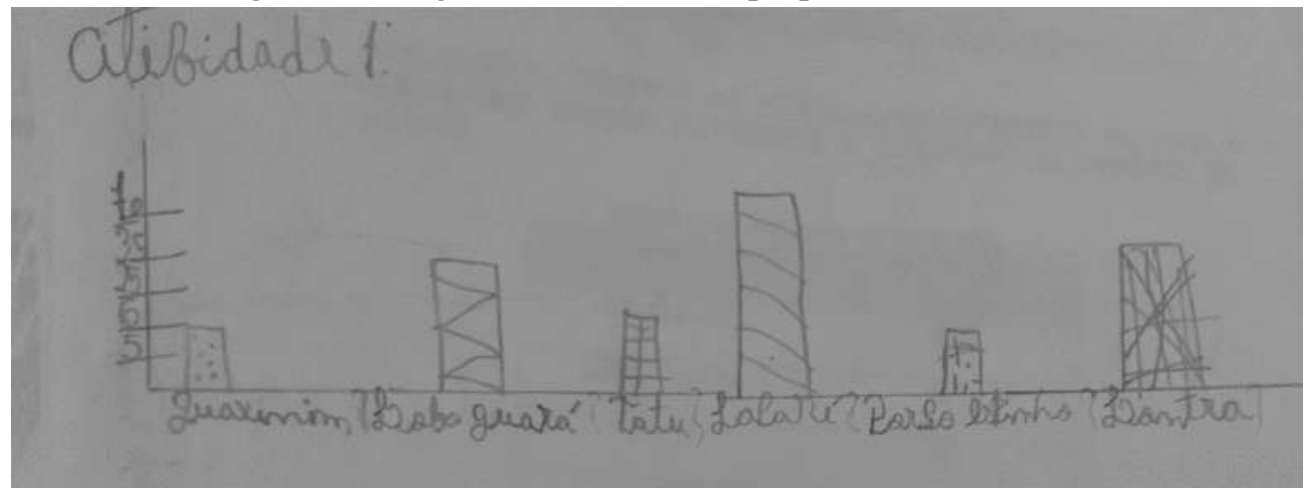

Fonte: as autoras

Os alunos apresentaram maior facilidade em criar escalas unitárias, como já levantado pela literatura. Entretanto, quando a situação envolvia escalas não unitárias, houve maior dificuldade. Guimarães (2002) e Cavalcanti e Guimarães (2010) já afirmavam que não só crianças, mas também adultos que frequentam os anos iniciais de escolarização têm dificuldades em compreender valores representados em uma reta numérica, considerando a proporcionalidade entre os valores expressos nela, ou seja, as subunidades. Essas autoras alertam para a importância de a escola trabalhar de modo sistematizado com as diferentes representações gráficas, oportunizando o contato com os diferentes tipos de gráficos e diferentes escalas.

O título do gráfico é um outro elemento constituinte da representação gráfica que anuncia o tema e deve informar a época à qual se referem os dados e o local onde ocorreu o evento. 
Figura 7 - Representação sem o registro do título do gráfico

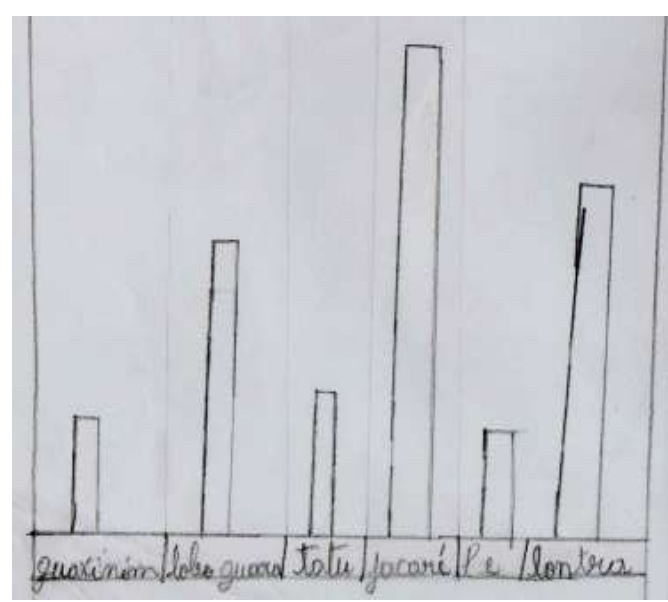

Figura 8 - Representação com o registro do título do gráfico

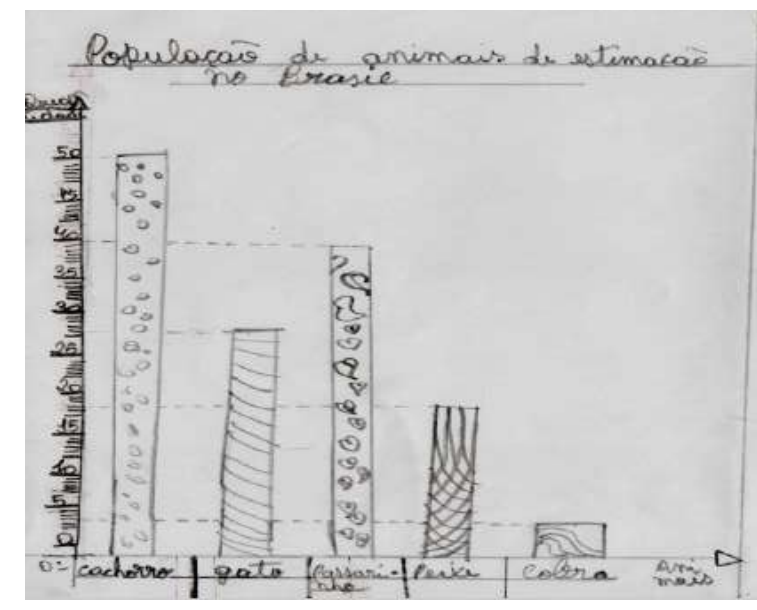

Fonte: as autoras

Identificamos que foi grande a ausência de título nas representações gráficas registradas nas atividades do pré-teste (Figuras 7 e 8). Acreditamos que esse baixo desempenho pode ser explicado em função da maioria das atividades propostas aos alunos, nos livros didáticos e nas escolas, envolverem a interpretação de gráficos e não a construção. Após a intervenção de ensino percebemos que os dois grupos avançaram em relação a essa categoria, independente do recurso utilizado.

O último elemento avaliado foi a fonte dos dados. Desejávamos identificar se os alunos registravam, na representação gráfica que construíram a fonte de dados registrada na representação tabular. Infelizmente, apesar de alunos dos dois grupos passarem a registrar esse elemento no pós-teste, foi de modo pouco expressivo, demonstrando que essa aprendizagem merece ser mais enfatizada. Fernandes (2014) também constatou, em seu estudo, que foram poucos os alunos que registraram o título, a fonte e nomearam as categorias.

Uma vez analisado o desempenho nas Atividades 1 do pré e do pós-teste, passamos a analisar as Atividades 2, comparando também os resultados entre o pré-teste e o pós-teste. Essas atividades envolviam a construção de um gráfico de barras múltiplas a partir da tabela de dupla entrada. O Gráfico 2 apresenta o desempenho dos alunos, em função do recurso utilizado na realização dos testes, na Atividade 2. Observa-se que, para o G1, houve uma diminuição dos erros e acertos parciais e aumento dos acertos totais. Já no G2, observa-se uma diminuição dos erros que passaram a ser acertos parciais. Uma das justificativas para tal é o fato de realizarem o pós-teste utilizando como recurso o lápis e o papel, o que desmotivou os alunos, como já relatado anteriormente. Outra justificativa possível, é que ver no software Excel a representação gráfica das barras múltiplas e discutir sobre elas foi menos 
eficiente para a aprendizagem do que construir as barras múltiplas com o lápis e papel, como fizeram os alunos do G1 durante a intervenção.

Gráfico 2 - Desempenho dos alunos na Atividade 2 por grupo e fase

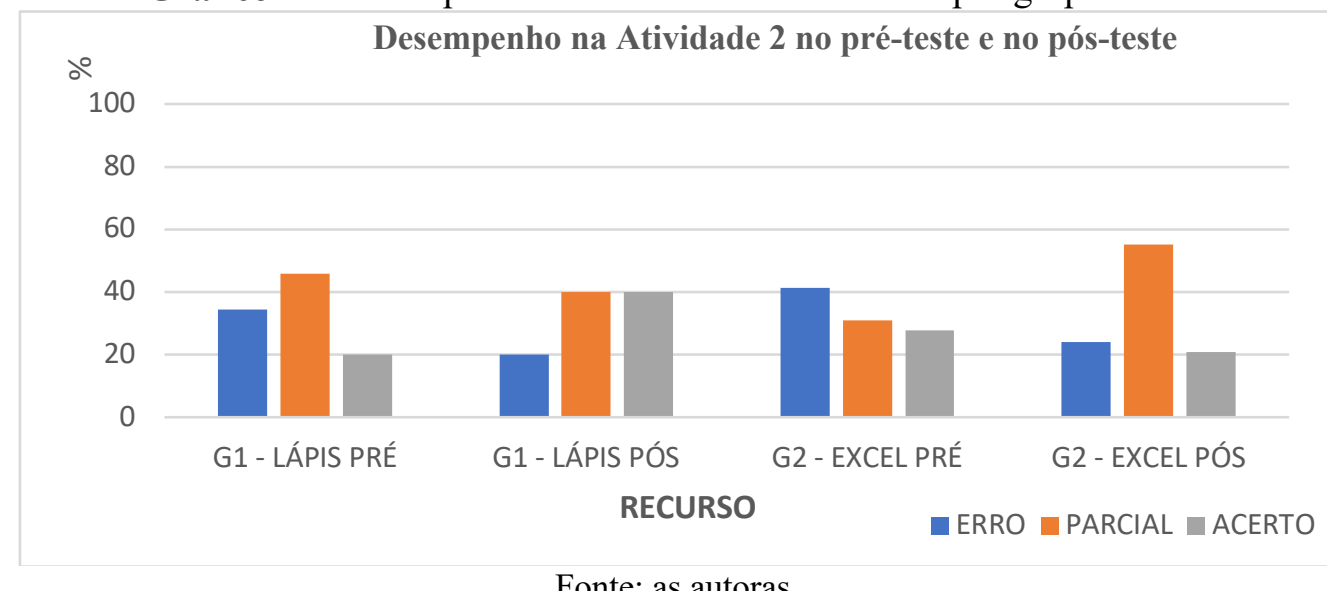

Analisando as respostas dadas pela aluna A16 (Figura 9), integrante do G1, pudemos observar que no pré-teste ela registrou os dados em dois gráficos e a escala conforme os dados apresentados na tabela, ou seja, sem respeitar a proporcionalidade dos intervalos. $\mathrm{Na}$ atividade do pós-teste, registrou a representação gráfica em apenas um gráfico e com todos os elementos necessários dessa representação, evidenciando sua aprendizagem.

Figura 9 - Representações gráficas de A16 nos testes
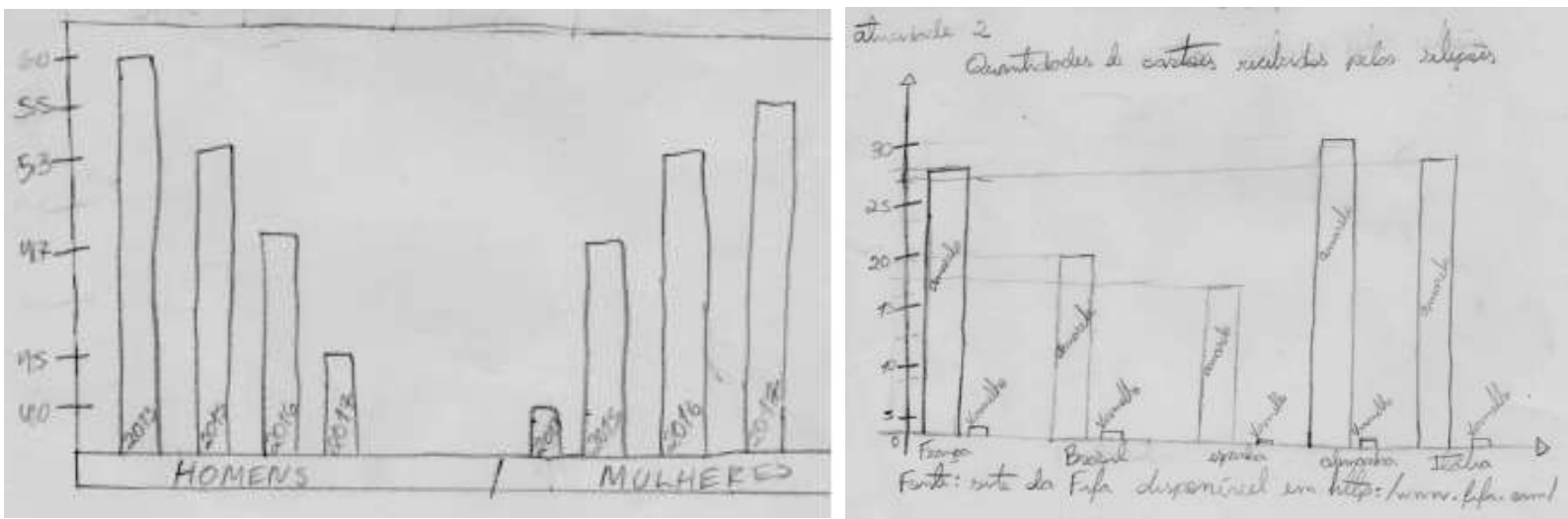

Fonte: as autoras

Para essa atividade também elencamos os elementos constituintes de um gráfico de barras duplas, para então classificar o que os alunos conseguiam registrar a partir dos seus conhecimentos. Consideramos como elementos constituintes de um gráfico de barras duplas: representação com os eixos de coordenadas, nomeação deles, barras iguais em largura e espaçamento no eixo x, escala, título e fonte.

Analisando as respostas dos alunos às questões do pré-teste, nos surpreendemos que alguns conseguiam registrar o gráfico de barras duplas, conforme resposta do Aluno A49 
(Figura 10), integrante do G2 já no pré-teste, porém, apresenta erros na proporcionalidade da escala. Na atividade do pós-teste, ele apresenta o gráfico de barras múltiplas corretamente e com elementos necessários dessa representação: eixos nomeados, barras proporcionais e nomeadas, título do gráfico, legenda dos dados apresentados. Percebemos que, em relação à escala, o aluno faz o registro da escala não-unitária, mas considera o intervalo unitário no registro do intervalo numérico.

Figura 10 - Representação do gráfico de barras duplas pelo Aluno A49
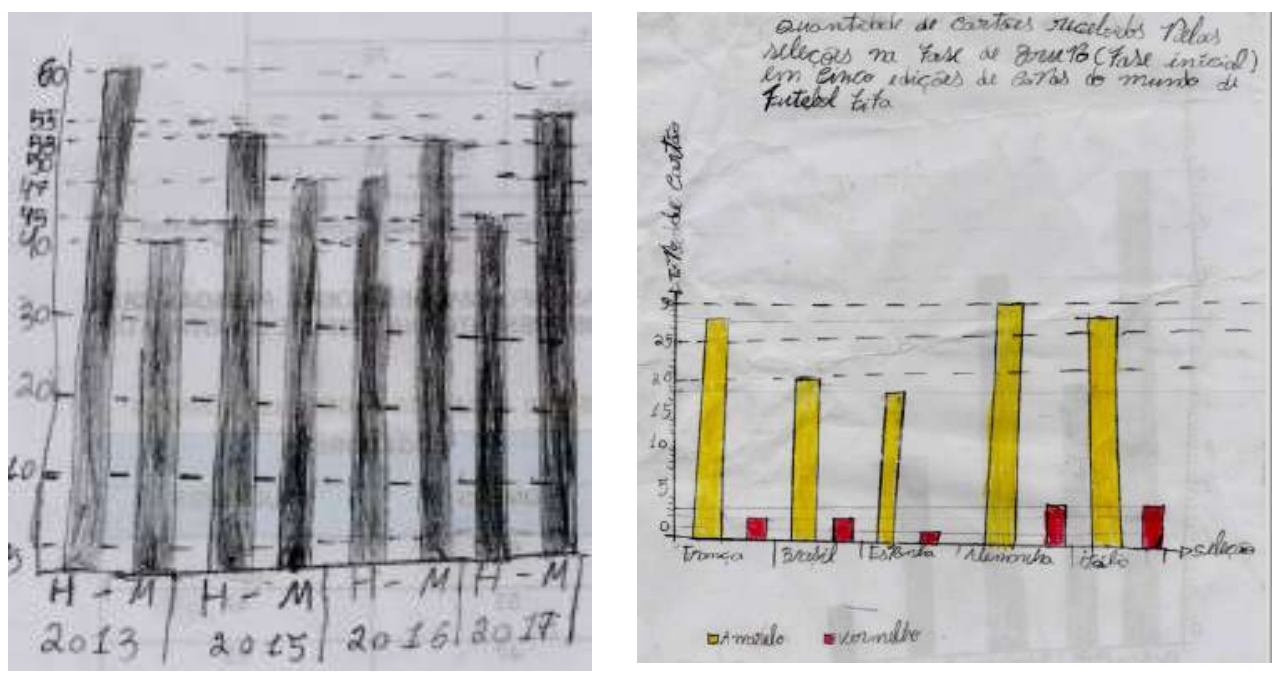

Fonte: as autoras

Em relação ao registro da representação gráfica dos dados, identificamos uma diminuição de respostas em branco para ambos os grupos. Nos dois grupos, observamos alunos, tanto no pré como no pós-teste, fazendo desenhos, quando os alunos registram traços do que acreditam ser um gráfico. No G1, observa-se um aumento no percentual de alunos que constroem um gráfico de barras múltiplas, já no G2 o percentual se mantém.

Sobre o registro dos eixos, esperávamos que os alunos, além de realizarem o registro do eixo de coordenadas, nomeassem cada um deles. Em ambos os grupos, os alunos passaram a nomear os eixos após a intervenção. Nesse processo, também analisamos as respostas deles em relação ao registro do nome das barras. Esperávamos que os alunos registrassem as barras e nomeassem identificando as categorias dos dados apresentados na tabela. Observamos que ambos os grupos avançaram em relação a essa categoria.

Sobre a representação da escala do gráfico, avaliamos se o aluno: deixou em branco, registrou valores apresentados na tabela ou com valores aleatórios, registrou a escala correta unitária ou registrou a escala correta não-unitária. No pré-teste, identificamos que a maior parte dos alunos não registrou a escala no gráfico construído. No pós-teste, observamos que o quantitativo de respostas em branco diminui para ambos os grupos. Constatamos também 
que, em ambos os grupos, vários alunos no pós-teste criaram corretamente escala unitária e não-unitária, o que era mais adequado nessa situação. Entretanto, muitos alunos de ambos os grupos ainda apresentaram erros na proporcionalidade da escala. Acreditamos que essa dificuldade, apresentada por eles aqui, pode ser superada se forem levados a uma reflexão mais sistemática e específica sobre a proporcionalidade dos intervalos necessária em uma reta numérica, conforme vivenciaram Evangelista e Guimarães (2015).

No registro da representação pelo Aluno A9 (Figura 11), na atividade do pré-teste, identificamos que ele não registra a escala, mantendo apenas a proporcionalidade entre as barras, representando um gráfico com barras separadas para cada gênero. Na atividade do pós-teste, ele registra a representação gráfica com uma escala não-unitária, com intervalo numérico proporcional e barras múltiplas, demonstrando que avançou no registro dos elementos constituintes de um gráfico de barras duplas. No entanto, confundiu-se no registro do intervalo numérico, demonstrando que compreendeu que o encontro dos eixos está o número zero, mas registra o intervalo de forma errada.

Figura 11 - Registro da escala nas atividades no pré e pós de A9
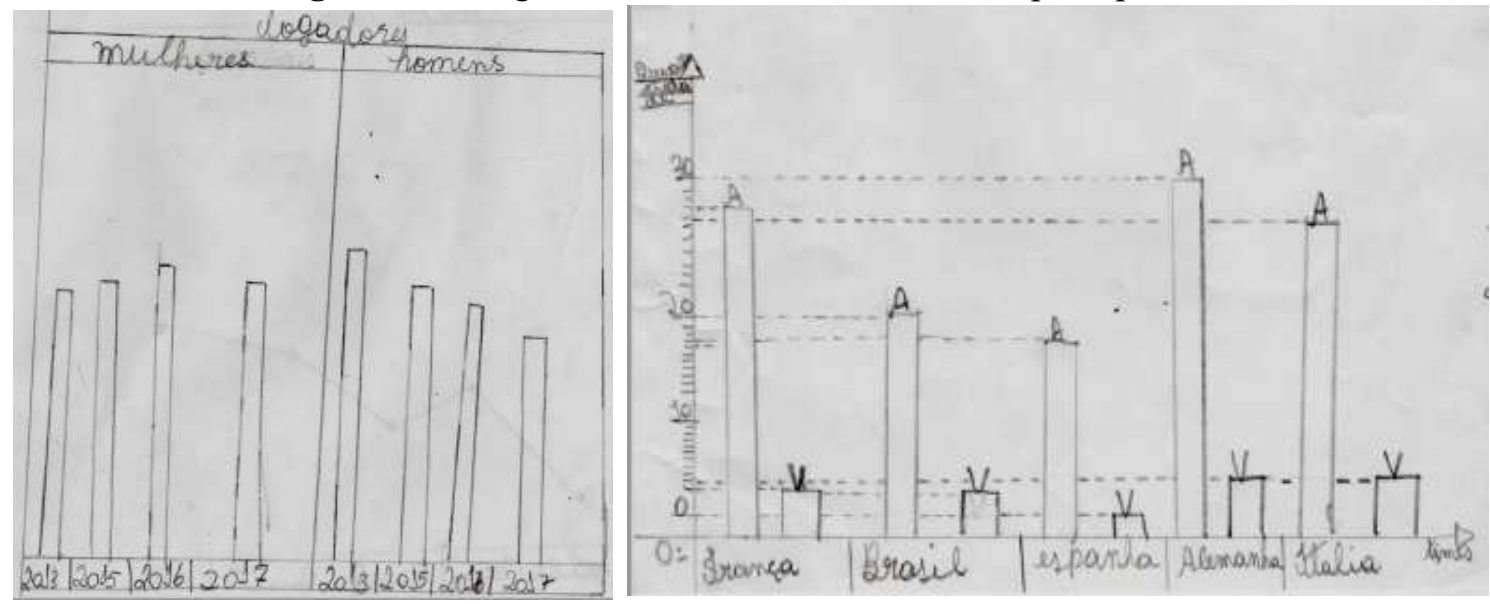

Fonte: as autoras

Em relação ao registro do título do gráfico, esperávamos que os alunos registrassem, uma vez que é um elemento constituinte da representação. De modo geral, percebemos que no pré-teste os alunos não escreviam o título do gráfico, tendo melhorado nesse quesito no pós-teste. Destacamos a importância de além de ler e interpretar os dados presentes na representação gráfica, o exercício de construí-la auxilia os alunos a entender o que dizem os dados e ajuda-os no registro da representação. Compreendemos que os alunos conseguiram assimilar a importância de registrar o título do gráfico, o que pode indicar que o aprendizado deles acerca dos gráficos de barras duplas foi ressignificado para além da leitura e interpretação dos dados apresentados. 
Sobre o registro da fonte na representação gráfica, esperávamos que os alunos registrassem a fonte dos dados presente na tabela. Porém, poucos fizeram isso, como mostra a atividade 1. Assim, a intervenção não foi suficiente para mobilizar os alunos sobre a importância do registro desse elemento.

O desenvolvimento da habilidade de retirar informações dessas representações é que possibilita às pessoas compreenderem, de fato, informações presentes, o que as torna capazes de desenvolver uma opinião crítica quanto às diversas situações presentes no cotidiano.

\section{CONSIDERAÇÕES FINAIS}

Esse estudo buscou investigar a aprendizagem de alunos do $5^{\circ}$ ano do Ensino Fundamental, em relação à compreensão da construção de gráficos, a partir de tabelas, com lápis e papel ou com o software Excel. De acordo com a BNCC (2017), no trabalho com a Estatística, a leitura, a interpretação e a construção de tabelas e gráficos têm papel fundamental para que os alunos compreendam a função da Estatística em seu cotidiano.

Em nosso estudo, defendemos que a construção e registo das representações gráficas pode ser o caminho para que os alunos se apropriem de habilidades essenciais para serem letrados estatisticamente. Entendemos que se apropriando dos elementos constituintes do gráfico estatístico, os alunos terão condições de entender melhor o contexto dos dados, ler e interpretar de modo mais amplo e também inferir e apresentar conclusões sobre os dados apresentados.

Percebemos que a sequência de atividades proposta na intervenção de ensino configurou-se como um bom recurso para o desenvolvimento das competências estatísticas dos alunos em relação à representação gráfica dos dados, oportunizando momentos de aprendizagem colaborativa e oferecendo uma prática pedagógica diferenciada, na qual eles tiveram a oportunidade de refletir sobre o que estavam realizando.

Concluímos que as atividades utilizadas na intervenção de ensino contribuíram para avanços qualitativos em relação ao desempenho e aproveitamento dos alunos em cada grupo. Dentre esses avanços, identificamos que o Grupo 1, lápis e papel, avançou na representação dos dados, considerando a proporcionalidade entre as barras e o registro da escala unitária e não-unitária. Acreditamos que ao utilizar o lápis e papel, os alunos tiveram que refletir mais sobre como representar os dados. Já os alunos do Grupo 2, que utilizaram como recurso o software Excel, focaram sua atenção nas diferentes visualizações dos dados que o software favorecia, mas não refletiram tanto sobre a escala, uma vez que ela já era apresentada automaticamente no programa. 
O uso da tecnologia, em geral, é apresentado como uma ferramenta que leva à aprendizagem. Nesse estudo, apesar de utilizarmos o software Excel como recurso tecnológico, ele não foi suficiente para determinar avanços significativos na aprendizagem dos alunos que o utilizaram. Pudemos perceber que o fato de refletirem sobre o processo de construção foi mais importante para a aprendizagem do que o uso da tecnologia. Porém, entendemos que o uso do recurso tecnológico pode oportunizar outra forma de aprender Estatística.

Ressaltamos, em nosso estudo, o papel da mediação da pesquisadora como um elemento diferencial na construção do conhecimento estatístico. Independente do recurso utilizado em sala de aula, é preciso que o professor tenha conhecimento sobre o conteúdo a ser ensinado, para que sua mediação oportunize momentos de reflexão e de entendimento sobre o conteúdo apresentado. No caso do nosso estudo, em que focamos na construção da representação gráfica, a partir dos dados apresentados em uma tabela, faz-se necessário o professor conhecer os elementos constituintes da reprodução gráfica, para assim promover reflexões e mediar a construção do conhecimento. Extrapolando, dessa forma, a prática de leitura e interpretação dos gráficos de barras.

A Educação precisa contribuir na formação de um aluno que seja verdadeiramente um cidadão crítico e consciente, de modo que ele possa participar e intervir ativamente no contexto social em que está inserido. Esperamos que essa pesquisa possibilite a ampliação das discussões sobre a importância de se ensinar a construção da representação gráfica como forma de promover o letramento estatístico dos alunos.

\section{REFERÊNCIAS}

BEN-ZVI, D. Statistical reasoning learning environment. Em Teia| Revista de Educação Matemática e Tecnológica Iberoamericana, v. 2, n. 2, 2011.

BIANCHINI, D. F; BISOGNIN, C.; SOARES, D. Uma proposta didática para o Ensino de Estatística: o uso do Excel para representação gráfica. Renote - Revista Novas Tecnologias da Educação, Universidade Federal do Rio Grande do Sul-UFGRS, v.17, n.2, 2015.

BIVAR, D; SELVA, A.C.V. Analisando atividades envolvendo gráficos e tabelas nos livros didáticos de matemática. Anais da XIII Conferência Interamericana de Educação Matemática - CIAEM, Recife, 2011.

BRASIL. Base Nacional Comum Curricular: Educação é a base. Ministério da Educação. Brasília, 2017. 
BRASIL. Parâmetros Curriculares Nacionais: Matemática, $1^{\circ}$ e $2^{\circ}$ ciclos do Ensino Fundamental. Ministério da Educação. Secretaria do Ensino Fundamental. Brasília, DF, 1997.

BUENO, C.; LIZIERO, A.; BORUCH, I.; KMITA, L.; FRANCZAK, M. Ensino de Estatística: uma proposta de atividade utilizando o Excel. Anais do Colóquio LusoBrasileiro de Educação - COLBEDUCA, Joinville, SC, 2016.

CAMPÊLO, S. Software educativo Tinkerplots 2.0: possibilidades e limites para a interpretação de gráficos por estudantes do Ensino Fundamental. Dissertação (Mestrado em Educação Matemática e Tecnológica), Universidade Federal de Pernambuco. Recife, 2014. $167 \mathrm{f}$.

CARNEIRO, R.; PASSOS, C. Vivências de professores de matemática em início de carreira na utilização das tecnologias da informação e comunicação. Revista Zetetike, v. 17, n.32, Cempem-FE-Unicamp, 2009.

CARVALHO, C. Reflexões em torno do ensino e da aprendizagem da estatística: o caso dos gráficos. Actas do II encontro de probabilidades e estatística na escola. Braga (Portugal), 2009. 22-36

CAVAlCANTI, M.; GUIMARÃES, G. Desempenho dos alunos dos anos iniciais na compreensão de escala. Encontro Nacional de Educação Matemática - ENEM, 2010, Salvador. Anais do X ENEM. Recife: SBEM, 2010.

CURCIO, F. Development graph comprehension: elementary and middle school activities. Reston, VA: NTCM, 1989.

DIAS, C. Ambiente virtual de aprendizagem para o ensino de Probabilidade e Estatística nos anos iniciais do ensino fundamental. Dissertação (Mestrado em Ensino de Ciência e Tecnologia), Universidade Tecnológica Federal do Paraná. Ponta Grossa, 2016.

DIAS, C.; SANTOS JÚNIOR, G. Ensino de Estatística e tecnologias da informação e comunicação: entre a docência e o desenvolvimento de recursos tecnológicos. Revista Brasileira de Ensino de Ciência e Tecnologia, v. 9, n1, 2016.

DINIZ, L. N. Leitura, construção e interpretação de gráficos estatísticos em projetos de modelagem matemática com uso das Tecnologias de Informação e Comunicação. Tese de Doutoramento em Ciências da Educação Especialidade em Educação Matemática, Instituto de Educação, Universidade do Minho, 2016.

ESTEVAM, E. J. G.; KALINKE, M. Recursos tecnológicos e ensino de Estatística na educação básica: um cenário de pesquisas brasileiras. Revista Brasileira de Informática na Educação, v. 21, n. 2, 2013.

EVANGELISTA, B; GUIMARÃES, G. Escalas representadas em gráficos: um estudo de intervenção com alunos do $5^{\circ}$ ano. Revista Portuguesa de Educação, v.28, 2015. 117 - 138.

FERNANDES, R. J. G. Estatística e probabilidade: uma proposta para os anos iniciais do ensino fundamental. Dissertação de Mestrado em Ensino de Ciência e Tecnologia, Universidade Tecnológica Federal do Paraná. Ponta Grossa, 2014, 191p. 
FERNANDES, J. A.; VISEU, F.; FERNANDES, M. C.; SILVA, M.; DUARTE, P. Uma intervenção de ensino em Estatística no ensino profissional através de investigações estatísticas. X Congresso Internacional Galego-Português de Psicopedagogia. Braga: Universidade do Minho. 2009.

GAL, I. Adult statistical literacy: Meanings, components, responsibilities. International Statistical Review, v. 1, n. 70, 2002.

GUIMARÃES, G. L. Interpretando e construindo gráficos de barras. Tese do Doutorado em Psicologia Cognitiva. Universidade Federal de Pernambuco, Recife, 2002. 